\title{
Foreign Language Teaching in Over-Crowded Classes
}

\author{
Halil Küçükler ${ }^{1} \&$ Abdullah Kodal ${ }^{2}$ \\ ${ }^{1}$ Balıkesir University, Balıkesir, Turkey \\ ${ }^{2}$ Istanbul Aydın University, Istanbul, Turkey \\ Correspondence: Halil Küçükler, Balıkesir University, Balıkesir, Turkey.
}

Received: October 5, 2018 Accepted: December 17, 2018 Online Published: December 20, 2018

doi: 10.5539/elt.v12n1p169 URL: https://doi.org/10.5539/elt.v12n1p169

\begin{abstract}
The importance of English in Foreign Language learning has been widely accepted in recent years and the English language is now well established as an international language. There is a growing significance of foreign language in education. As English has been widely used internationally, many people are interested in English and prefer learning English. When it is considered in public schools, English teaching has become more intense in school curricula. There are many barriers in language teaching in from primary education to higher education. One of the most important barriers in foreign language teaching is crowded especially over crowded classes. In crowded classes, classroom management, getting results from language approaches becomes difficult. In addition to this, a small number of class hours per week is another barrier in language teaching. The purpose of this study is to examine this issue and to examine the question of how language teaching is handled in these crowded classes and what different activities are useful to apply. If the educators are unable to change the classroom order, what are the appropriate language activities and how to apply them.
\end{abstract}

Keywords: large/over-crowded classes, language activities, foreign language teaching

\section{Introduction}

A class is referred to as overcrowded when the actual number of students surpasses the expectation in the teacher or lecturer's contract. Pre-kindergarten classes are required to have 18 or fewer students; kindergarten classes are set at 25 , grades one through six are set at 32 . College classes are set at between 30 and 33, and high school are set at 34.Therefore any class that is above average of 30 is overcrowded. In today's world, it is not uncommon to see classes with 40, 50, 60 and 70 students. The quality of education is reduced and the whole essence of learning is jeopardized with such overcrowded classes. In this paper, we look at the problems of overcrowded classes and its implications, we examine up to the technologies that are being used to manage classrooms, we look at pairing and group work to encourage cooperative learning, teaching experience in large classes and the conditions for learning English language in large classes.

\subsection{Overcrowded Classrooms}

Most people disregard the fact that "crowded" and "overcrowded" concepts are not the same. Classes bigger than 25 usually do not give students and instructors the chance to engage literary texts through concerns, conversation, and writing. Overcrowding occurs when the number of students is more than the space in room. The high amounts of learners in one single class inhibits instructors from training efficiently and learners from learning effortlessly. Quite simply, when we say overcrowded we mean it is exaggerating, it is beyond the means. Otherwise, it might not be an issue. Throughout this paper, the definition of overcrowded and large classes are utilized interchangeably to refer an university language course contains 50-60 students which pose genuine challenge the delivery of knowledge and learning to all students.

\subsection{Problems and Implications of Overcrowded Classes}

Teaching in a classroom that is overcrowded be discouraging, overwhelming, and stressful. A classroom that is full, faces challenges that can feel nearly impossible to conquer, even towards the most effective teachers there is not enough of the trained instructor to go around. Pupils perform better when the instructor can offer one on a single or little team instruction on a regular basis (Makielski, 2018). This becomes increasingly difficult to do as classroom size increases.

A teacher passes knowledge to everybody. Each student has his own way in internalizing the foreign language 
through the teachers explanations. In big classes, it is difficult to establish an interaction that is sufficient all students due to the overwhelming amount of pupils in a course. Challenges such as monitoring attendance, checking assignments, maintaining control, checking comprehension and many more are typical issues worrying language instructors involved with big class teaching. Opposite to the various opinions on the definitions of big classes. Many scientists agree in terms of dilemmas associated with training overcrowded classes. Big classes are seen as common problems including: The physical environment associated with classroom, the matter of management, engaging student into the learning process, difficulties of assessing student's knowledge and feedback, as well as the problem of teaching resources.

Overcrowding increases classroom discipline dilemmas. More students offer more opportunities for personality conflicts, stress, and basic behavior that is disruptive. Perhaps the most useful teachers battle to manage a classroom that is overcrowded and will end up spending more time managing their class than they do training (May 2018).

\subsubsection{Inability to Assess Student's Knowledge and Feedback}

Struggling students fall further behind. Average and unhealthy pupils will struggle even more to advance in a full class. These pupils need more direct instruction, one-on-one instructional time, and minimal distractions to maximize their learning potential. In big classes, the possibilities that lots of pupils can complete a entire term or semester of research without experiencing good conversation with the tutor is quite high. The evaluation procedure is significantly different in big to the small classes. The interaction between teachers and students through spoken or written feedback produces higher students' gains due to increased retention, greater scholastic accomplishment, development of critical reasoning and having greater aspirations". The absence of such personalized feedback reduces their chances of attaining meaningful outcomes for many students. As a result, this could easily lead to dropping out, bad performance, noncompletion, and reducing their inspiration to master. With a large class, instructors aren't able to evaluate students' work continuously (Leah, 2018).

\subsubsection{Management Issue}

Classroom management refers to all of the things that a teacher does to organize student's space, time, and materials so that learning can take place. Some students benefit from the large number of students and escape from the lecture without notice. Such students photocopy lecture notes from their colleagues instead of attending themselves. Thus, overcrowding resulted in a high rate of absenteeism among students and teachers.

For instance, if the students are too many, they make a loud noise and consequently, the teacher cannot control them. The overall noise level is increased. It is an expected outcome whenever there is a boost in the number of students within the classroom. Louder classrooms translate to distractions making it more difficult for students to understand as well as for instructors to show (Makielski, 2018).

\subsubsection{The General Setting}

The general setting plays a key role to promote effective learning. Some individuals give no value towards the real setting of the classroom from teaching effectively until they encounter problems. Classrooms with large numbers of desks and chairs often prevent instructors from doing the kind of interactive tasks that they wish to do". There are some key problems. One of them is a limited space classroom with a potential of student increase. Secondly, teachers cannot monitor groups when there is no room to walk around the room and cheating becomes a problem when you cannot be everywhere and consequently students lose concentration and don't comprehend their lessons. Consequently, it is vital to identify that the environment that will influence the way instructors and students think and act. Instructor anxiety is increased, often leading to instructor burnout. More students translate to more stress. Numerous and exceptional instructors are opting to go out of the career they deal with on a daily basis because it is not worth the stresses - absence of personal connections. Teachers would not get to know other pupils well, and the right time these people were in a position to invest in each pupil individually would have reduced (Makielski, 2018).

\subsection{Teaching Large Classes}

Probably one of the most issues voiced by language instructors is how exactly to keep their classroom disciplined in classes with significant enrollments and how to grade large volumes of written work. Instructors can relieve those nagging dilemmas using some strategies. In the first place, teachers should earn some efforts to learn the real names of theirstudents. It is tough to keep in mind all students' names. One way that is simple would be to have the pupils say their names if they ask a question. Also, the instructor can ask pupils to have a valid title card that they show in their front. Second, establishing ground rules, instructorsfind it advantageous to set rules on the first day of lecture. Abiding by these rules by both instructors and pupils will encourage students 
to be engaged large classes are always a big concern. It may be essential to separate students into groups to complete grammar exercises. This maydecrease the range documents teachers must correct. Second, for several written works, it may be essential to have each student go through the means of self-editing and one or two rounds of peer editing beforeturning in the paper. This decreases the quantity of written assessment that the instructor needs to provide.

\subsubsection{Fostering Active Learning}

Keeping learners engaged through the whole program is perhaps not an easy task especially when the wide range of learners is beyond the standard that is normal. Giving students time to remember what they learned by stopping lecturing every fifteen minutes is an effective strategy. Furthermore, welcoming them to write questions or reviews on index cards and let them have to the instructor by the end of class is a fantastic strategy. Think-Pair-Share is an ice-breaking that is a good ideal for big classes. The teacher ask the whole class, then gives them a few moments to think, then group them, and they discuss with each other. Finally, invite students to talk about reactions. In this full situation, students could be more open to being involved in future class talks.

Another strategy is certainly one-moment paper. The instructor asks pupils to take a sheet out of paper as well as for 1 minute, summarizes details of lecture or notes any specific points of the lecture. Then, the teacher gathers the papers and makes use of feedback to target problem areas. This will help assess the student's comprehension and locate the problems that are potential.

\subsubsection{Using up to Date Technologies}

\subsubsection{Video Conferencing Technology}

Distance learning technology in the classroom enables educators to do more with less. For schools working with increasingly shrinking budgets and overcrowded classrooms, it may be the solution that is comprehensively increasing education in every school or university campuses. Video conferencing technology provides students with the ability to connect to other pupils, guest lecturers, specialists, and instructors across multiple campuses if not one other part worldwide (Cornelius, 2013). Educators can achieve more pupils by training and interacting with them in numerous areas, and rural schools could offer classes that are previously unavailable. Students may also collaborate with other students and talk to experts in other countries. Video conferencing technology in the classroom may not be compact and mobile like their smartphones or iPads, but it will still create well experienced which will get student excited and involved as ever (Candarli \& Yuksel, 2012). Exactly What pupil would not be delighted about touring a place or chatting along with their buddies in Asia?

\subsubsection{Virtual Reality}

Digital reality may be used in classrooms to boost pupil learning and engagement. VR can transform the way academic content is delivered; it works by creating the premise of making a virtual world - real or imagined and allows users to interact with it. Being immersed in what motivates a great learning environment. It will require a less cognitive load to process the info (Jovanne, 2018).

Here are a few properties that make VR so powerful for education.

\subsection{Learn by Doing}

It is a fact that is well-known people learn best by doing; however, if one inspects modern education, then one will see how small learning takes place by doing. Students are focused on reading directions rather than with them in practice.

VR offers an experienced anchor towards the instruction. With VR, learners are motivated to discover for themselves. Pupils have a chance to discover by doing things instead of by reading a book (Kendric, 2018) — a medicine that is virtual where there's no danger of things going incorrect.

\subsection{Emotional Reaction}

Visceral reactions from what we are experiencing are fundamental to forming memories. VR makes it simple to engage students each time making their experiences unforgettable.

The emotional connections students make with learning during Virtual Reality increase their excitement and help them remember details that are different.

\subsection{Visual Learning}

Many people are visual learners - VR is this combined group of learners. Rather than reading about things, pupils can see the things they are learning. To be able tovisualize functions that are complex mechanisms means they are simpler to understand. 


\subsection{Group Learning}

Several of the essential knowledge we acquire does not come from what we hear from lecturers, but rather from collegiality and debate. VR provides the option making learning experiences social by permitting students to keep in touch with each other. Using avatars and mapped expressions that are facial people can come together to discuss, synthesize, and study from the other person.

\subsection{Distance Learning}

VR we can bridge the space between educators and learners. With VR, distance education tools can put educators and pupils together in the room that is same electronic representations of themselves - teachers can teleport into the VR world and guide students through their experiences.

\subsubsection{Using Pairing and Group Work to Encourage Cooperative Learning}

Cooperative training is especially very therapeutic for any pupil learning a language that is second. Cooperative training activities promote peer conversation, which assists the development of language and also the learning of principles and content (Shaw, 2018).

There are a few popular strategies that can be used with all pupils to learn content (such as science, mathematics, social studies, language arts, and foreign languages). Nonetheless, they have been especially beneficial to ELLs for learning English and content at the same time. Most of these strategies are especially useful in teams of four;

\subsubsection{Round Robin}

Present a category (such as "Names of Mammals") for discussion. Make students take turns going around the group and naming items which fit the category.

\subsubsection{Roundtable}

Found a category (such as words that start with "b"). Have students take turns writing one term at the same time.

\subsubsection{Writearound}

For imaginative writing or summary, offer a sentence starter (for example: If you give an elephant a cookie, he will ask for...). Ask all learning students in each team to finish that phrase. Then, they pass their paper towards the right, see the one they received, and put in a sentence compared to that one. After having a few rounds, four great tales or summaries emerge. Provide kiddies time and energy to add a conclusion and edit their favourite with all the course.

\subsubsection{Numbered Heads Together}

Ask pupils to total down within their groups from a single to four. Announce question and a period restriction. Students place their minds together to create an answer. Call the right quantity and have all students with that number to face and answer the question (Kilic, 2014). Recognise correct responses and elaborate through rich conversations.

\subsubsection{Team Jigsaw}

Assign each student in a group $1 / 4$ of a web page to see from any text (e.g. a social studies text), or $1 / 4$ of the subject to investigate or memorize. Each student completes his / her assignment after which shows others or helps to put together a united group item by contributing a piece of the puzzle.

\subsubsection{Tea Party}

Pupils form two concentric groups or two lines dealing with each other. Ask questions (on any content), and students discuss the response with the student dealing with them. After 1 minute, the surface circle or one line moves towards the right in order that students have to brand new lovers. Then pose a question for them to talk about. Continue with five or more concerns. For a small variation, pupils can write questions on cards to examine for the test through this "Tea Party" technique. After every learning, there is a cooperative activity to debrief all the kiddies by asking questions such as just what was the study on this task? How was the feeling using teammates? Do you improve working together if we do this again, how will?

\subsection{Experiencing Teaching in Large Classes}

Teaching a large class poses numerous challenges, both inside and out of the class. In the classroom, high enrollments can market student disengagement and emotions of alienation that may erode students' feeling of obligation and result in habits that both show and promote lack of engagement (McGee \& Weimer, 1988). Logistics can be a challenge whenever teaching a large class. Massive courses have grading problems familiar to teachers across a selection of disciplines. On the one hand, we do not wish to have a lot of graded projects 
ourselves down with incessant grading that we bog. On the other hand, we do wish to have sufficient assessments; we have a fair grading system for our students and ourselves (Richard, 2018).

Cheating is widespread in college courses big and small; however, in massive courses, it may be especially challenging to identify cheating when it occurs. That is because we are grading this type of high number of exams, essays, and assignments that the sort of careful analysis often essential to identify cheaters is more difficult. We might perhaps not understand our students and their activities as well, and it is that knowledge that typically assists university trainers in identifying cheating when it is taking place (White, 1974). As anyone who has proctored an exam for $100+$ pupils can attest, it can be extremely tough to maintain with everything that's going on inside our little city-sized courses (White, 1974).

\section{Ideal Conditions to effective Language Learning in Classrooms}

The conditions of English language learning depend on different academic institutions. This means that these conditions are not comparable because every country has their system of educational curriculum and needs. The essential requirements include motivation, class arrangement, syllabus design, and the experience of language and communication in the classroom (Heejung, 2014).

\subsection{The Learning Process}

To study a foreign or second language, learners need to practice it exceptionally usually. The more learners practice the four skills, the more they attain mastery of language learning. Every student must indeed be offered maximum possibility and sufficient time and energy to be exposed to language training performance. Foreign language exposure is essential for the practice of the four aspects of foreign language context i.e. reading, speaking, writing and listening (Stæhr, 2008).

\subsection{Approaches to Teaching}

Language may be the agent of any civilization or culture. Instructors teaching English should be modern and updated. Teaching is about creating possibilities for students to work on their understanding, to interact with new information. The core problem of language teaching is the 'How,' i.e., how exactly to teach languages? Every teacher needs their methods, especially when dealing with big classes. In universities, the trusted training technique remains the lecture technique, particularly in large classes (Stæhr, 2008). As a result, the relationship between the teacher and learners becomes more of lecturer-centered rather than student-centered approach. Instructors must use the most recent and effective communicative ways to show languages such as communicative language training, task-based language teaching, cooperative language learning, and content-based instruction.

\subsubsection{Communicative Language Teaching (CLT)}

CLT is a set of principles that guide how a student learn a language, the kinds of classroom activities that best facilitate learning, and the roles of teachers and learners in the classroom. Activities in CLB are numerous; they basically necessities information gap to be filled. For instance, role plays jigsaw activities, puzzles, games, map reading, dialogues, and many other tasks. The teacher facilitates the communicative process as well as acting as an independent participant within the learning-teaching group. One of the characteristic features of communicative language teaching is put emphasis on both the structural and real life situation characteristics of communication.

\subsubsection{Task-Based language Teaching}

A task is piece of classroom work that allow students to understand, manipulate, produce or interact in their target language with attention focused on mobilizing their grammatical knowledge in order to express meaning". In task-based-learning "students are presented with a task they have to perform or a problem they have to solve". Firstly, the teacher introduces his students to the topic using different ways such as reading part of a text as lead in to a task. After that, the task cycle phase students first perform the task in pairs or small groups. Second, they to plan how are they going to present what they achieved. Finally, they report to the whole class either orally or in writing. The last stage is language focus where students analyse specific features of any task they performed before or the teacher gives a practice focusing on some features of language.

\subsubsection{Content-Based Instruction}

Content-Based Instruction integrates the presentation of topics or tasks from subject matter classes (e.g., math, social studies) within the context of teaching of a foreign language. Language use draws on integrated skills. Students are engaged in tasks associated with the four skills. The use of media can enhance English learning; but this is not the case with large classes with restricted resources. 


\subsection{Using ICT in Teaching English to Large Classes}

Making use of technology can play a vital role in presenting lectures. It encompasses various techniques that are useful for facilitating communication, for example, mobile phones, radio, video, television, computer systems, and satellite systems among others. Technology tools such as information projectors, overhead projectors, projection screens, sound system, computer and DVD player, control panel and wireless microphones make the training experience more fulfilling and exciting. Technology helps students to ask and responding to questions comfortably. ICT may contribute to great learning in large classes. Nonetheless, this technology could never replace the teacher (Muchlis, 2015). There is entirely no learning process without the teacher.

\section{Conclusion}

There is a continuous misconception about what a large class is. It is relative because it is difficult to specify. There are many challenges to large classes which causes problems in the teaching and learning process. However, teachers can see this as an opportunity to turn the challenge into solution by using strategies that will help them maximize learning in such large classes. These strategies are very effective and will allow the students and teachers to collaborate and learn effectively in the classroom.

Success is achieved in large classrooms when a high level of motivation and interest is given to a topic. Possessing an understanding of teaching approaches helps the teachers, and having adequate teaching resources such PPT, tape recorders etc. help enhance learners' performance and produces a learning environment that is friendly.

\section{References}

Candarli, D., \& Yuksel, H. (2012). Students' Perceptions of Video-Conferencing in the Classrooms in Higher Education. Procedia - Social And Behavioral Sciences, 47, 357-361. https://doi.org/10.1016/j.sbspro.201 2.06 .663

Cornelius, S. (2013). Facilitating in a demanding environment: Experiences of teaching in virtual classrooms using web conferencing. British Journal of Educational Technology, 45(2), 260-271. https://doi.org/10.11 $11 /$ bjet.12016

Heejung, J. (2014). A new paradigm of English learning: Comparative analysis of English learners' behaviors among face-to-face, e-learning, and smart English learning environment. English Language Teaching, 26(1), 241-258. https://doi.org/10.17936/pkelt.2014.26.1.012

Jovanne, N. (2018). Virtual vs Classroom Training. Retrieved from https://trainingmag.com/virtual-vs-classroo m-training

Kendric, E. (2018). Virtual Reality and Education - Virtual Reality Society. Retrieved from https://www.vrs.org. uk/virtual-reality-education/

Kilic, F. (2014). Content arrangement strategies used by the academic staff. International Journal of Academic Research, 6(1), 443-449. https://doi.org/10.7813/2075-4124.2014/6-1/B.59

Leah, J. (2018). The Problems and Solutions to Overcrowding in Modern Cities Research Paper - 1286 Words. Retrieved from https://www.studymode.com/essays/The-Problems-And-Solutions-Of-Overcrowding-1137 $942 . \mathrm{html}$

Makielski, A. (2018). The Problem With Overcrowded Classrooms. Retrieved from http://www.theprospect.net /the-problem-with-overcrowded-classrooms-11001

May, L. (2018). Effects of Overcrowded Classrooms On Teacher- Student Interactions Retrieved from http://www.academia.edu/4550569/Effects_Of_Overcrowded_Clasrooms_On_Teacher-Student_Interactions

McGee, R., \& Weimer, M. (1988). Teaching Large Classes Well. Teaching Sociology, 16(4), 477. https://doi.org/ $10.2307 / 1318184$

Muchlis, M. (2015). The Implementation of Technology Approaches to Develop Learners' Autonomy in Learning English. Al-Ta Lim, 22(3). https://doi.org/10.15548/jt.v22i3.144

Richard, L. (2018). Learning Environments: Large Classes - UCF Faculty Center for Teaching and Learning. Retrieved from http://www.fctl.ucf.edu/TeachingAndLearningResources/LearningEnvironments/largeclass. php

Shaw, C. (2018). Think, Pair, Share Cooperative Learning Strategy. Retrieved from https://www.teacher vision.com/group-work/think-pair-share-cooperative-learning-strategy 
Stæhr, L. (2008). Vocabulary size and the skills of listening, reading and writing. Language Learning Journal, 36(2), 139-152. https://doi.org/10.1080/09571730802389975

White, J. (1974). How to Handle Large Classes. Improving College And University Teaching, 22(4), $262-266$. https://doi.org/10.1080/00193089.1974.10533607

\section{Copyrights}

Copyright for this article is retained by the author(s), with first publication rights granted to the journal.

This is an open-access article distributed under the terms and conditions of the Creative Commons Attribution license (http://creativecommons.org/licenses/by/4.0/). 